\title{
THE PROBLEM OF THE HYPERMETROPIC MINER
}

\author{
BY \\ A. Christie Reid \\ NOTTINGHAM
}

AlL familiar with working conditions in a coal mine are aware that the myopic miner who consistently wears his correction on the top can dispense with his glasses below ground, and can, even with a considerable error, work without these up to an age that

- is often surprising, even at the coal face under modern strenuous conditions. Not so the high hypermetrope who has to accommodate to see his work, because a miner's work is done mostly within arms' length.

I - am not aware that any systematic enquiry into the working capacity of the latter has ever been made, and the remarks in this paper may serve as an introduction to the subject.

In the last two or three years I have collected some twenty cases of hypermetropic miners, who have come to me or been sent for compensation reports, in whom the error had to be taken into account in assessing the working capacity. Most were complicated cases in which other factors were at work, e.g., amblyopia in one eye, loss of one eye, corneal nebulae, nystagmus old or recent; and it is often a very difficult task to estimate fairly the emphasis one should put on the refractive error apart from these.

No compensation would be allowed for an error alone, but if an accident had spoiled the better eye, say, in a squinter, the visual result might be so poor that the man would have to leave the pit, being thrown back on to an eye with very poor vision. One asks, therefore, whether any standard of manifest error might be accepted as barring a man at a specific age from working in the pit, and also what symptoms; if any, may arise from the strain involved in the more or less continuous act of accommodation required for accurate work in the dim light of the mine with dark-adapted eyes.

All cases to be discussed save the last one had a manifest error of over two dioptres in the best axis of the better eye. One would not expect to meet with any serious difficulty below fifty years of age with less than this.

The general nervous make-up of the man must be taken into account, and one does meet with a few cases in which even a moderate error seems to lead to a train of nervous symptoms that demand a change from the pit bottom to the surface at a comparatively early age. I have three cases that have had to leave 
the pit before thirty in whom, with both eyes not far from normal and with no appreciable nystagmus, symptoms were fairly severe.

CASE 1.-C.S., aged $28 \frac{1}{2}$ years, had come out only fourteen days before seeing me. He had never had glasses. Complaint : terrible headaches over months while doing face work. Unaided vision $R$. $6 / 36$ one letter, L..6/18. R. with $+3.56 / 9$. L. with $+2.56 / 9$. Together $6 / 6$. $^{\circ}$ As he said he could not go on he was advised to leave the pit, and agreed to do so.

Perhaps it should be explained that the most strenuous and the best-paid work is at the face getting the coal, or " ripping work" at the face, usually involving a good deal of pick work, even when cutting machinery is used, and in poor light. The pace is severer since the working hours were shortened, and the physical strain, apart from eyes, very great. Maintenance work on the roads up to the face is considered a degree less exacting.

CASE 2.-W.H., aged 30 years, wore glasses at school, gave them up, but at 22 had to resume for wear out of the pit. R.V. +4 with +0.5 cyl. $180^{\circ} 6 / 12$ slowly. L. +5 with +1 cyl. $\mathrm{I} 65^{\circ} 6 / 36$. He had done ten years at the face but for the last eight months had not made a full week because of headaches and dizziness. Had to cease work a month ago. Certifying surgeon found no nystagmus. Referred to me. Unaided V. R. 6/60. L. less than 6/60. Glasses correct. No nystagmus. Advised to work on surface in glasses.

CASE 3.-R.R., aged 27 years, was at coal face without serious difficulty till sixteen months ago, when he received a severe blow at $R$. inner orbital angle. The eye not affected. This may have upset his nerve, for though he tried the face again, after a year of irregular work he had to give in on account of severe headaches. He then took to dairy work with great relief. He had no glasses before the accident. I found unaided V. R. and L. less than $6 / 60$. No nystagmus. $R$. with +4.5 and +1.5 cyl. $150^{\circ} 6 / 9$ part. L. +5 and +1 cyl. $140^{\circ} 6 / 24$. I gave opinion that he never should have gone down the pit and was not entitled to compensation.

I am afraid that cases such as these three are too common. Many are wrongly certified as nystagmus, which may be present, but it may not be of a degree to incapacitate. Once branded as a nystagmic, the miner has difficulty in getting employment of any kind elsewhere, while if he remains at his own pit his case is a prolonged source of difficulty to the management.

How prevent such from going down? Advice to parents before leaving school does some good, but a few fairly high hypermetropes are not spotted at school if they have no squint, and 
especially if both eyes function well. Every case of squint applying for pit work should be referred to an ophthalmic surgeon. A few alternators may be passed by him if the error is not high, but any with a definite amblyopia without correction should be rejected. Routine pit-head vision testing is impractical as being liable to be referred to a non-expert. Witness a recent case I had to get out of the pit-a lad of nineteen who had adopted the old dodge of crossing his hands and blocking the amblyopic eye while being tested. It is a kindness to bring such cases of early breakdown out of the pit while not too late for them to learn another trade.

This leads to the consideration of a second group, of which I can quote eight examples in which an amblyopic eye with or without a squint is present. In these there is perhaps more liability to accident-hence, more come to examination. These cases had to give up work at ages from twenty-eight to forty-two, but they need not all be detailed.

CASE 4.-Seen at clinic, aged 30 years, found to have +3 error manifest. R. corrected $6 / 9$. L. less than $6 / 60$ and no central fixation. No serious accidents. Glasses given for wear out of the pit, and to persevere in the pit. This he did for five years, then developed nystagmus and left the pit. He now reports, at thirty-six years of age, after a period of work on the bank, great improvement in his nystagmus symptoms and can do full work on the top.

I do not regard the error of refraction as having contributed to any nystagmus that may have been present in any of my cases. This point has been gone into on many occasions since my article on Miners' Nystagmus in the British Journal of Neurology, Brain, 1906 , in which I sought for a physiological explanation for nystagmus, and found it in a disturbance of the equilibration of the eyes. It is doubtful if. we have gone much further than this since then. I have still to find a miner who wears plus glasses at face work. I have heard of a few who have worn minus. But all the men and all the officials I question scoff at the idea of continuous wear in a hot, dusty place such as most of the men have to put up with. I have never been able to persuade a man to try it.

CASE 5.-T.L., the oldest in this group, actually carried on in the pit despite a high error till $42 \frac{1}{2}$ years, then a severe blow spoilt the L. eye (which I think must have been a good eye) and made him come out. After the accident, R.V. +6.5 6/9. L.V. +7 less than $6 / 60$. Wearing glasses, he is now doing labouring work at a munitions depot, but reports, five months after the accident, that his eyes become blurred towards the end 
of the day, and that he has difficulty getting home in the black-out. One accepts this, knowing how loss of sight in one eye in a man over forty years makes him very helpless in dark-adaptation conditions.

CASE 6.-A.S., aged 30 years, is one of a kind that we are meeting with under war conditions-a man who left the pit under my advice in 1940 and did good work on the bank, but who went down again under pressure after three months. Though put to work below on roads only, he broke down after two years with severe headaches. This was despite wearing glasses below to correct a high error. R. +4.5 with +2.5 cyl. $90^{\circ}$ less than $6 / 60$. L. +5 with +1 cyl. $90^{\circ} 6 / 9$ part. This man was advised to come out finally. It was a big risk going down again, and he should not have agreed.

CASE 7.-W.P. illustrates the difficulty of getting a high hypermetrope off the compensation list. Seen at thirty-six, he had had compensation for five years following a blow on the $\mathrm{R}$ : eye. He had worked these five years on the bank. I found no sign of trauma, but a squinting amblyopic eye that could not fix. Error about +4 with +2 cyl: at $90^{\circ}$ less than $6 / 60$. L. +3 with +1 cyl. $90^{\circ} 6 / 9$. No nystagmus even after exercises. I agreed that he was not a case for compensation, and I doubted how long he had really been entitled:

CASE 8 is a border-line case with a degree of nystagmus. W.H.S., aged thirty-eight years, came out with nystagmus at thirty-one and, after surface work till thirty-four, went down again and stuck it till two months-ago, when he came up for illness. Having recovered from this, the question was should he go down again? I found $\mathrm{R}$. $+2.56 / 12$ slowly. L. $+3.56 / 60$. A very fine nystagmus was seen with the ophthalmoscope, but not aggravated by swinging body movements. There was no characteristic attitude and no photophobia. He did not notice lamps dancing when last down the pit. I advised him to resume work on the top wearing glasses, and that compensation should cease. I was of opinion that it would be asking for trouble on both sides to send him down again.

Other such border - line cases between the hypermetropic syndrome and that of nystagmus could be quoted. Some of them are accident liable, and even on road maintenance work good near vision is essential for the detecting of flaws in the roof, defective wooden props, etc. (Steel props do not bend but may break suddenly without warning.)

CASE 9 was fortunate in having a safe job on a road haulage. stationary engine below ground. J.E.W., aged thirty-seven years $\left(R .+3.5\right.$ with +0.75 cyl. $90^{\circ} 6 / 9$. L. +4.5 with +1 cyl. 
$75^{\circ} 6 / 24$ ), had had to give up general maintenance fitting work below as he "could not wear glasses at this work" because of dust and sweat. Despite his complaint of retro-ocular pain and a decided light sensitiveness during examination, I advised him to carry on with his engine. He had worn correcting glasses at this work.

Four of my cases had returned, in late middle life, for one reason or another, to the pit after a spell on the top, but could not stick it after a certain period.

CASE 10.- E.W., aged 59 years, after fifteen years surface work, went down again on the national emergency call for more coal getters. After two-and-a-half years with increasing discomfort, he had to give up owing to a series of minor accidents and severe headaches. R. +4.5 less than $6 / 60$. L. $+3.56 / 6$ part. He had been wearing glasses on the top but could not at the face.

CASE 11 was in a sorry plight with " nerves," and had had several accidents. S.E., aged fifty-two years, got glasses, for near work only, some years ago. He had left the pit because of eyes nine years ago and had worked well on the top. On appeal, he went down again, but after eighteen months had to cease. No nystagmus. $R$. +3 with +1.5 cyl. $70^{\circ} 6 / 18$. L. $+3 \cdot 5$ with +1 cyl. $906 / 9$. Two months after coming out again he came to see me, looking a new man, and was doing full work on the top. - CaSE 12.-W.B., aged 48 years, had been " ripping " (i.e., on road maintenance work in the pit) for four years after losing the L. eye from an acute septic (hypopyon) ulcer. The error was not high. R. +1 with $+2 \cdot 25$ cyl. $110^{\circ} 6 / 9$ part : unaided $6 / 18$. He had this, but had not worn it in the pit. 'He had now daily headaches, felt uncertain at work, numerous minor accidents, off work last three weeks with bruised back. I had no doubt about his willingness and also his disability, and advised him to come out finally.

CASE 13.-J.S., aged 62 years, lost R. in accident at face. Has done light work on roads in pit for twelve years wearing correction +5.5 L. $6 / 18$ almost : unaided less than $6 / 60$; no nystagmus; eye otherwise normal. There is much dread of light, dizziness on stooping, and he is very helpless after dark. I reported that he was fit only for labouring work on the top, and considered that his symptoms were entirely due to eyestrain, but that this would have been manifest even if he had had both eyes, for in that case he would probably not have been given light work and any breakdown would obviously have been due to the large error alone. I considered that he had no claim for compensation now.

I shall quote only one other case, which is of interest as having been quite recently referred to a referee. 
CASE 14.-J.B., aged 60 years, a highly intelligent pit "deputy" (supervisor), had no trouble till after a recent accident that led to loss of one eye. He had not worn distant correction before the accident even on the surface. The error was slight, $+1 \cdot 25$ with +0.25 cyl. $90^{\circ} 6 / 6$ : unaided $6 / 18$ almost. Since the accident he had resumed work below (i.e., going round the workings wearing the glasses), but headaches, severe and continuous, such as he had never before experienced made him feel unable to continue. I reported in his favour and advised that he should leave the pit, considering that had he had both eyes he would not have had the symptoms. This opinion was contested by another ophthalmic surgeon and the man sent to a referee, who upheld my opinion. Having myself an error of $+1.5 \mathrm{sph}$., and only at sixty-five taken to wearing distance correction, I do not place much emphasis on an error of that grade in a man of sixty; but when such a man has suddenly lost one good eye, the discomfort and difficulty seem to be considerable in the dim light of a mine.

The above cases may be taken as fairly typical of the points I wish to raise. I find that of seven cases which had an error of between 2 and 4 dioptres in the lowest axis, the age of breakdown averaged thirty-seven years, the extremes being twenty-eight and forty-four years. Over +4 few can go on beyond thirty years at the coal face. With 6 or more probably no man should go down below, and few do. It would therefore seem reasonable to advise lads with both eyes good not to go down if the error is 3 or more, and squinters or amblyopes not at all. Much, too, can be done in advising parents when a boy is about to leave school. If a pit accepts a man with a defective eye, it is accepting a risk, for in addition to being accident-liable, accident to the good eye may render him incapable; and even accident to the poor eye in a hypermetrope may. necessitate glasses much earlier than would have been the case otherwise.

Finally, one hopes that this enquiry may stimulate interest in the hypermetropes in other industries in which lighting conditions leave much to be desired. I know of none that puts so severe and continuous a strain on the worker. Perhaps night engine-drivers and airmen who fly at night approximate, but the work is not so prolonged. These already have been tested and selected.

As to the exact location of the strain, I do not think it can be all put down to the ciliary muscle. The mental interpretation of small visual objects may be a factor. We can call the symptoms a neurosis, but that does not make them less real. Is it possible that, in the conflict between the call for a wide pupil in the dark and that for contraction of the ciliary muscle, a conflict that is the opposite of what is demanded in daylight, we have the making of a neurosis? 